\title{
Impact of urbanization on thermal environment of Chengdu-Chongqing Urban Agglomeration under complex terrain
}

Si Chen ${ }^{1,2}$, Zhenghui Xie ${ }^{1,2^{*}}$, Jinbo Xie ${ }^{1}$, Bin Liu $^{3}$, Binghao Jia ${ }^{1}$, Peihua Qin ${ }^{1}$, Longhuan 5 Wang ${ }^{1,2}$, Yan Wang ${ }^{1,2}$, Ruichao $\mathrm{Li}^{1,2}$

${ }^{1}$ State Key Laboratory of Numerical Modeling for Atmospheric Sciences and Geophysical Fluid Dynamics, Institute of Atmospheric Physics, Chinese Academy of Sciences, Beijing 100029, China

${ }^{2}$ College of Earth and Planetary Sciences, University of Chinese Academy of Sciences, Beijing 100049, China

$10{ }^{3}$ School of Software Engineering, Chengdu University of Information Technology, Chengdu 610225, China

*Corresponding author: Zhenghui Xie (zxie@lasg.iap.ac.cn)

Abstract. Located in the mountainous area of southwest China, the Chengdu-Chongqing Urban Agglomeration (CCUA) was rapidly urbanized in the last four decades, has led to a three-fold urban area expansion, thereby affecting the weather and climate. To investigate the urbanization effects on the thermal environment in the CCUA under the complex terrain, we conducted the simulations using the advanced Weather Research and Forecasting (WRF V4.1.5) model together with the combining land-use scenarios and terrain conditions. We observed that the WRF model reproduces the general synoptic summer weather pattern, particularly for the thermal environment. It was shown that the expansion of the urban area changed the underlying surface's thermal properties, leading to the urban heat island effect, enhanced by the complex terrain further. The simulation with the future scenario shows that the implementation of idealized measures including returning farmland to forests, expanding rivers and lakes can reduce the urban heat island effect and regulate the urban ecosystem. Therefore, the urban planning policy can has potential to provide feasible suggestions to best manage the thermal environment of the future city toward improving the livelihood of the people in the environment.

\section{Introduction}

With urban area expansion, the CCUA's lower surface has changed compared with the natural land surface, leading to the heat island effect, which is also an important factor in global warming(Kalnay et al., 2003; Kawashima, 1975; Ning et al., 2019). As one of the most dramatic land-use changes, urbanization alters land surface physical properties, including albedo, emissivity, heat conductivity, and morphology, making urban areas exhibit greater heat capacity, Bowen ratio, and roughness(Robaa, 2011 ). The impermeability of urban land surface reduces water vapor evaporation and increases sensible surface heat. The multiple reflection and absorption of radiation in the urban canopy make the energy absorbed by a city in the daytime more difficult to dissipate in the form of long-wave radiation at night. These 
height (PBLH), thermal structure, and local/regional atmospheric circulation(Kawashima, 1975; Oke, 1995; Berling-Wolff et al., 2004; Hamdi et al., 2010; Hamdi et al., 2010;) . Therefore, it is imperative to assess the changes in urbanization and develop adaptation strategies.

Numerical simulation has been used to investigate the urban heat island effects on cities, such as Tokyo, 1996 ; Wang et al., 2020 ). Urbanization also changes a city's precipitation by enhancing the spatial heterogeneity of the rainfall or making it extreme (Yang et al., 2019). Urbanization of cities in the arid and semi-arid areas can cause pronounced urban drying (Robaa, 2011 ). For cities under complex terrain conditions, their weather and climate are often exacerbated by the interaction of complex terrain with urbanization (Ning et al., 2018 ; Yang et al., 2019 ). On the other hand, cities will face severe water and heat stress (Zhao et al., 2021 ). Therefore, the demand for a suitable plan to alleviate stress is exigent.

In this study, we investigated the interaction of complex terrain and urbanization on the thermal environment of the urban agglomeration for CCUA, located in the mountainous area of southwest China. We further researched the effects of land-use planning policies on the heat stress of the urban area. This research (1) clarifies the urban warming pattern caused by the urban expansion of the CCUA in the past, (2) measures the combined impact of complex terrain and urbanization on the summer urban thermal environment, and (3) reveals the potential of implementing the measures of returning farmland to forest and grassland and expanding the area of rivers and lakes to alleviate heat stress in the CCUA.

\section{2: Data and methodology}

\section{$20 \quad 2.1$ Weather Research and Forecasting (WRF) configuration and study area}

We used a numerical model WRF-ARW v4.1.5 (Skamarock et al., 2008), coupled with a single-layer urban canopy model (SLUCM) and the Noah land surface model (Noah LSM, Niu, G.Y., 2011; Z.L. Yang,G.Y., 2011,), to study the impact of urbanization on the regional thermal environment. We chose CCUA as the study area, set up three one-way nested domains in the horizontal direction (Fig. 1a), with resolutions of $1 \mathrm{~km}, 5 \mathrm{~km}, 25 \mathrm{~km}$ respectively, and divide the atmosphere into 32 vertical layers. July, the hottest month in 2018, was selected as the simulation period, and the first $48 \mathrm{~h}$ of the simulation results was discarded as the spin-up time of the model. The forced initial field data simulated in the model was the re-analyzed data of operational global analysis and forecast data, which are on $0.25 \times 0.25$ degree grids, prepared operationally every six hours, from National Centers for Environmental Prediction. The main

30 physical schemes for the model selection are the following: the microphysics scheme as the Thompson et al. Scheme; the long-wave radiation scheme as the RRTM scheme ( Mlawer, E.J.,1997); the shortwave radiation scheme as the Dudhia scheme ( Dudhia, 1989 ); the near-ground layer and boundary layer schemes as the Revised MM5 surface layer scheme (Monin and Obukhov, 1959); the land surface scheme as the Noah Land Surface Model; the planetary boundary layer as the BouLac PBL (Hong et al., 
The urban environmental conditions of CCUA are similar, depending on the same comprehensive transportation network, with two megacities (Chengdu (CD) and Chongqing (CQ)) as the core city, and the other 14 smaller cities distributed among them, thus forming a large urban agglomeration(Wang et al., 2015 ; Xiaojuan et al., 2018 ). The CCUA is located in the Sichuan Basin in the central and southern

5 Asian continent (between latitude 28"10' and 32.25'), surrounded by the Qinghai-Tibet Plateau, Daba Mountain, Huaying Mountain, and Yungui Plateau(Wang et al., 2015 ). The surrounding mountains are primarily between 1,000 and 3,000 meters above sea level. Compared with plateaus and plains, the topography is overly complicated. The Sichuan Basin is relatively humid, situated in the mid-subtropical zone, and it also has marine climate characteristics(Richardson, 2008 ). In winter, the temperature in this area is the highest at that latitude. This is due to the occlusion of the terrain, and the rich cold air is blocked by the surrounding plateaus and mountains(Yuan and Xie, 2012 ). The annual precipitation in the Sichuan Basin is 1,000 to 1,300 mm(Shao et al., 2005 ). The mountain areas on the western edge of the basin have higher annual precipitations $(1,500-1,800 \mathrm{~mm}$ ), a prominent rainy area in China(Yuan et al., 2012).

\subsection{Land-use change and land-cover datasets}

The underlying surface influences factors, such as soil thermal conductivity, vegetation impedance, reflectivity, roughness, and thermal inertia. The thermal inertia, in turn, affects the boundary layer structure and the land surface process. Therefore, more refined underlying surface information will improve the model simulation effect significantly.

WRF has two default land-use dataset types: the Advanced Very High-Resolution Radiometers from the US Geological Survey (USGS) and Moderate-resolution imaging spectroradiometer (MODIS). The acquisition time of USGS data was from April 1992 to March 1993, while MODIS's latest land-cover data was in 2010. The default data accuracy is low, and the timeliness is not enough, restricting the simulation accuracy of the model. Therefore, we replaced the WRF default data with the more accurate land use data. We get the 30-meter spatial resolution fusion land cover data for the two periods (viz. 1980, the Historical Scenario (Fig. 2a) and 2018, the Urban Scenario (Fig. 2b)) from the Institute of Geographic Sciences and Natural Resources of the CAS (Resource and Environment Science and Data Center https://www.resdc.cn/data.aspx?DATAID=264/). They were developed and verified in detail from medium-resolution satellite images. In this study, the land use types of the dataset were reclassified into

17 categories according to the International Geosphere-Biosphere Project classification scheme (USGS, 2003). Impervious surfaces of towns, industrial and mining lands, and roads were integrated as urban land-use types. After statistically calculating the land cover, it is found that from 1980 to 2018, the growth of urban land use types in the CCUA increased to nearly 9,000 square kilometers, which shrank the area of dry land, paddy field, and water wetland. According to the more accurate land use data in 1980 and 2018, urban land-use type is larger and can better reflect the actual situation of the underlying surface of the CCUA (Fig. 2). 
To explore the impact of urbanization on the thermal environment of the CCUA based on the 2018 land use and land cover dataset, we replaced the urban land type with the nearest natural land use type of the patch. Here, we term the land data set without city type "No Urban Scenario (Fig. 2c) ". In addition to the three land-use scenario data, we also planned and designed a Future Scenario land use of urban agglomeration landscape to explore the mitigation effect of landscape planning on the thermal environment stress of urban agglomeration (see Section 2.3 for details). All the five land-use datasets with a 30-meter resolution were resampled for $1 \mathrm{~km}$ as the underlying surface data of the model in the simulated area.

2.3 Planning of the inner ecological corridor and surrounding ecological barrier in the urban agglomeration

Urban agglomerations are brand-new regional units that have emerged from industrialization and urbanization into a higher stage (Bruinsma and Rietveld, ; Jun et al., 2012 ; Kawashima, 1975 ; Strange, 2008 ). The CCUA the most vitality region with a high potential for economic development in southwest China (Wang et al., 2015; ). However, the urban agglomeration is an extremely sensitive area where a series of ecological and environmental problems are highly concentrated and intensified(Bruinsma and Rietveld, ). For such ecological environment pressure, we can design and plan ecological corridors and ecological barriers in landscape ecology according to the natural geography, vegetation ecology, water system, and topography of urban agglomeration. It is expected that these ecological corridors and barriers can alleviate the urban heat stress caused by urbanization, meeting the growing cultural demands of the people.

Based on the land-use dataset of the Urban Scenario, we designed the ideal land use and land cover scenarios in the future, the Future Scenario (Fig. 2d), according to the guidelines for restoration of mountains, rivers, forests, fields, lakes, and grasses issued by the State Department of Ecological Environment and the development plan of the CCUA issued by the State Council. The specific method is to return farmland to forest and grassland in the five ecological protection areas around the urban agglomeration (Sichuan-Yunnan Forest Reserve, Qinba Biodiversity Ecological Function Zone, DaXiao-Liang Mountain Water and Soil Conservation Ecological Function Zone, Wuling Mountain Ecological Diversity and Soil and Water Conservation Ecological Function Zone, and Three Gorges Reservoir Water and Soil Conservation Ecological Function Zone). Eight land ecological corridors and seven water system corridors were designed according to the hills, mountains, and water systems in the urban agglomeration. In the corridor, the farmland should be returned to grassland to expand the river lake wetland (Fig. 2d). By comparing the Future Scenarios land use and the Urban Scenarios land use, we expect that the planned landscapes will improve the thermal environment of Urban Agglomerations in the summer, enhancing the living comfort in the urban agglomerations.

\subsection{Experimental design}

To study the impact of urbanization on the surrounding environmental and meteorological elements, 
seven experiments were designed as described in Table 1: five types of land use scenarios ("WRF Default Scenario", "History Scenario", "Urban Scenario", "No-Urban Scenario", and "Future Scenario") and two type of terrain conditions ("Topography (Fig. 1b)", the current situation of the original complex terrain of the CCUA, and "No-Topography (Fig. 1c)", that is smoothing the mountainous terrain around the CCUA). We smoothen the terrain to explore the effect of complex terrain on the summer weather of the CCUA. The physical parameterization schemes and simulation time periods, as well as the study area, were the same as those mentioned in the previous section, except the underlying surface land use datasets and terrain changes.

First, to verify the results of "Urban Scenario" and "Topography" (exp. 5), the land use data-driven model can reproduce the weather conditions in July 2018 more accurately than the "WRF Default Scenario" (2010 MODIS) vs. "Topography" (exp. 1). We compared the experimental results of exp. 5 and exp. 1 with the observation data of the National Meteorological Information Center of China Meteorological Administration. Secondly, by subtracting the results of "No-Urban Scenario" and "No-Topography"(exp. 4) from "Urban Scenario" and "No-Topography" (exp. 3), we compared the influence of the single urbanization factor on the thermal environment of urban agglomeration. Then, the result of exp. 5 minus exp.3 was taken as a single terrain factor affecting the thermal environment.

Topography directly affects the local atmospheric circulation. Here is a research question: will topography interact with urbanization to jointly affect the thermal environment of urban agglomerations? We refer to Yang's method to explore the interaction between this terrain and urbanization before we quantified the impact of urbanization on the thermal environment of urban agglomeration under complex terrain, i.e.,[ exp. 5 - (exp. 3 + exp. 6) + exp. 4 ] (Yang et al., 2019). By comparing exp. 5 and exp. 2, we quantified the impact of urbanization on the thermal environment under complex terrain. Finally, by comparing the land-use of Future scenarios after planning (exp. 7) with the current situation (exp. 5), we can explore whether landscape planning inside and outside the urban agglomeration can alleviate urban heat stress.

\section{Results and discussion}

\subsection{Model verification}

To verify the model performance, we compared the simulated monthly and daily mean spatial temperature models in July 2018 with the WRF default land-use dataset and with observations of the meteorological stations (Fig. 3a, 3c, and 3e). The correlation coefficient matrix of the 2018 Land use simulation results have a high spatial correlation coefficient $(\mathrm{p} \leq 0.05)$ over the whole the CCUA region (Fig. 4), Ten variables' correlation coefficient was calculated, such as the surface skin temperature (TSK), $2 \mathrm{~m}$ air temperature (T2)、ground heat flux (GRDFLX)、 upward heat flux at the surface (HFX)、 latent heat flux at the surface (LH)、 downward latent heat flux at the surface (LW_dw)、 upward latent heat 
coefficient matrix shows that the configuration of the model is reasonable. However, the simulation underestimated the surface $2 \mathrm{~m}$ air temperature by $0.75 \sim 2.5{ }^{\circ} \mathrm{C}$ compared with observation (Fig. $3 \mathrm{~b}$ ). Previous studies had reported similar bias, characteristic of the WRF model (Wang et al., 2015; Wang et al., 2013), with most overestimations occurring in the urban areas of the respective study areas.

5 Furthermore, the model exhibited a large negative deviation in the mountainous area around the CCUA (Fig. 3b) due to the systematic error of underestimating wind speed and temperature in the area. The Root-Mean-Square-Error between the observed and exp.5 (Urban Scenario \& Topography) simulation results was about $-2 \sim 4{ }^{\circ} \mathrm{C}$ (Fig. 3d). The spatial distribution of the correlation coefficient between the observation and the monthly mean $2 \mathrm{~m}$ temperature simulated by exp.5 is shown in Fig. 3f. It has a high correlation in the whole urban agglomeration. Since we are concerned with the air temperature changes caused by the land cover and terrain interaction of different underlying surfaces, some systematic deviations can be offset by the sensitivity experiments rather than the accurate reproduction of the absolute temperature in the study area.

\subsection{The interaction of complex terrain and urban expansion}

\section{$15 \quad$ 3.2.1 Topography effect}

To explore the impact of terrain on the thermal environment of urban agglomerations in the summer, we made the land use of the CCUA constant (No-Urban Scenario), compared the results under the two different terrain scenarios: original complex terrain (Topography) and smoothed topography (NoTopography). Comparing Fig.5a with Fig.5b, we can see that the influence of terrain on the temperature pattern is basically consistent with the current distribution pattern of summer monthly average temperature, and terrain is the main factor determining the temperature pattern. In Fig. $5 \mathrm{~b}$, the temperature inside the CCUA (compared with flat terrain) increases by about $10{ }^{\circ} \mathrm{C}$ when there is complex terrain. Simultaneously, the temperature in the plateau and mountainous areas around the CCUA decreases by more than $10{ }^{\circ} \mathrm{C}$. The complex terrain would form a lower temperature plateau mountain climate than the smooth plain terrain.

Sichuan Basin, where the CCUA is located, has a concave landform. The closed topography leads to low wind speed in Sichuan Basin, making the heat in the basin difficult to dissipate. Therefore, the thermal environment here is more severe than that in the flat terrain. In Fig. $6 \mathrm{c}, 6 \mathrm{~g}$, and $6 \mathrm{k}$, we observed that the complex terrain would increase the HFX and LH of the urban agglomeration. At the same time, due to

30 the high altitude around the basin itself, it will significantly raise the atmospheric boundary layer of the urban agglomeration. These are the crucial attributions for the temperature rise caused by the complex terrain.

The many rivers in Sichuan Basin make the southeast monsoon convey large quantities of water vapor, blocked by the mountains around Sichuan Basin. The southeast of the mountainous area is low, which is favorable for receiving water vapor. On the contrary, the northwest Mountainous area is of relatively high altitude, thereby conducive to water vapor loss, causing increased air humidity. Therefore, the topography 
is pertinent to forming a humid and hot climate in summer in the CCUA.

\subsubsection{Urban effect}

To determine the summer warming caused by a single urban land expansion factor, we conducted two groups of experiments: exp. 3 and exp. 4. Both groups of experiments smoothed the terrain to eliminate the influence of complex terrain. We observed that the urban expansion would cause the temperature of the whole urban agglomeration region to increase by $\approx 0.8^{\circ} \mathrm{C}$ (Fig. $5 \mathrm{c}$ ). Especially in the core areas of urban agglomeration (CD and $\mathrm{CQ}$ ), the temperature increased significantly, nearing $1.0^{\circ} \mathrm{C}$ increase in the main urban area. The temperature inside the urban agglomeration was considerably higher than on the outside, attesting to the "heat island effect."

Urbanization will significantly change the surface albedo, heat capacity, and thermal conductivity of the underlying urban surface. The change of surface heat flow caused by urbanization is shown in Fig. $5 \mathrm{c}$. The urban impervious surface absorbs more shortwave radiation downward, and the GRDFLX is stored more in the daytime and released more at night. Daytime surface temperature is mainly due to the increase of urban surface HFX, with a maximum increase of $90 \mathrm{~W} / \mathrm{m}^{2}$ in the core urban area of CD and CQ (Fig.

$6 b)$. The HFX rise directly elevates the near-surface temperature. Due to the impervious city surface, the city's evapotranspiration was lower than that of the suburb, and the LHduring the day was significantly reduced, the maximum reduction can reach $110 \mathrm{~W} / \mathrm{m}^{2}$ (Fig. 6f). The warming effect caused by urbanization enhances the turbulence and increases the PBLH (Lin et al., 2008). Also, the variation area and high-value area of the PBLH (Fig. 6i,6j) are the temperature variation area, concentrated in the core urban area. Here, the urban PBLH increased by $40 \sim 170 \mathrm{~m}$. Therefore, under the same external meteorological conditions, the HFX of urban construction land was higher, the LH was lower, and Bowen ratio was higher when compared to the vegetation coverage area around the city. The HFX and Bowen ratio of the urban surface were significantly higher than those of surrounding vegetation. This occurrence increases the heating of the urban surface into the lower atmosphere, an important mechanism of the urban heat island effect.

\subsubsection{Urban-Topography interaction}

By comparing the results of exp. 3, exp. 4, exp. 5, and exp. 6, we conclude terrain is the most crucial factor in forming local weather and climate pattern. In the case of complex terrain and urbanization, the terrain would affect the weather and climate simultaneously, causing climate change (Fig. 5d, 6d, 6h, and 61). Compared with the urban warming effect (caused by a single urbanization factor), the warming effect of the urban core area is more evident after the complex terrain is added. The warming areas are more concentrated in the urban core area. The average temperature in the core areas of CD and CQ increases by more than $1.5^{\circ} \mathrm{C}$.

Due to the joint influence of topography and urban expansion, the HFX increased by about $30 \mathrm{~W} / \mathrm{m}^{2}$. the LH increased by $30 \sim 60 \mathrm{~W} / \mathrm{m}^{2}$, extensively in the southwest of the CCUA, while the LH in the northeast of CCUA decreased by $20 \mathrm{~W} / \mathrm{m}^{2}$. The boundary layer of the city has been raised significantly, 
especially in the main urban areas of CD \& CQ, with the highest elevation of $180 \mathrm{~m}$.

Considering the heat flux, temperature, boundary layer and other factors mentioned above, we think that the topography further enhances the heat island effect in the CCUA and the urban core area of CD\&CQ.

\subsection{Historical warming of urban agglomerations}

5 In front, we quantitatively studied the influence of different factors on the urban thermal environment, such as single urban factor, single topography factor and the combined influence of urban and topography factors. The results reveal in detail the mechanism of how these factors affect the urban thermal environment.

To determine the summer warming caused by historical urban land expansion, we calculated the simulated 2-m air temperature difference between the urbanized land use in 2018 and the historical land use before urbanization in 1980 (Fig. 7a 7c) by the exp.1 \& exp.5. The whole region experienced some warming, with notable ones occurring in areas consistent with the location of the urban grid in 2018. At the same time, the northeast part of the urban agglomerations was warmed, probably resulting from the urban agglomerations effect or terrain hindering heat dissipation. The monthly average temperature of 2 m air in July of 2018 was $0.75{ }^{\circ} \mathrm{C}$ higher than that of 1980 . The most significant temperature increase occurred in the main urban area of CD and CQ. The maximum temperature rise reached $0.8{ }^{\circ} \mathrm{C}$. Note that the anthropogenic heat was not considered in the simulation process of this study. Therefore, the simulated warming is attributed to the increase of urban land only. Fig $7 \mathrm{~d} \sim 7 \mathrm{f}$ shows the frequency distribution of the heating amplitude of all grid points of CCUA, the warming range of CD urban area is between $0.5^{\circ} \mathrm{C}$ and $1.1^{\circ} \mathrm{C}$, while that of CQ urban area is between $0.4{ }^{\circ} \mathrm{C}$ and $0.8^{\circ} \mathrm{C}$.

Fig. $9 \mathrm{a}, 9 \mathrm{~b}$, and $9 \mathrm{c}$ show the diurnal variation of surface temperature, 2-m air temperature, and PBLH in the summer of the CCUA, CD, and CQ in 1980 and 2018, respectively. Here, regardless of the CCUA, $\mathrm{CD}$, or $\mathrm{CQ}$, the daily average surface temperature and the temperature of $2-\mathrm{m}$ air simulated by the 2018 urbanization scenario were significantly higher than those of the 1980 historical scenario, and the daily average atmospheric boundary layer represented by the histogram is also increased by $50 \sim 100 \mathrm{~m}$.

Compared with Fig. 10a and 10b, the change of surface radiation balance caused by urbanization was evident. The impervious surface layer of the CCUA absorbed more downward shortwave radiation, and the GRDFLX storage was larger during the day, while the GRDFLX released was larger at night. The surface temperature increased mainly through the HFX of the urban surface before gradually relieving from the HFX. The HFX reduction directly elevates near-surface temperature. Due to the decrease in soil evapotranspiration, the LH decreased significantly. From 1980 to 2018, large cities exhibited reduced soil moisture and near-surface wind speed, resulting in a lowered evaporation. The higher the surface temperature, the more intense was the long-wave radiation, and the higher the net radiation energy lost in the daytime. Similar scenarios ensued for the main urban areas of CD and CQ because the proportion

35 of impervious surface was higher. Changes in the surface heat flux became more apparent (Fig. 10c, 10d, 10e, and 10f). 
The two columns on the left side of Fig. 11 show the components of surface heat flux during the simulation period caused by urbanization. The upper and lower endpoints of the box graph represent the maximum and minimum values of the heat flux, while the middle, upper side, and lower side represent the average, $1 / 4$, and $3 / 4$ quantiles, respectively. The four boxes from left to right in each subgraph represent the ground heat flux Surface heat flux, HFX, LH, and Rn. The scatter points and curves on the right side of the box represent the distribution of surface heat flux values. Thus, it is easy to affirm that the mean and maximum values of HFX and Rn increased from 1980 to 2018. Similarly, in CD and CQ, the impervious surface area was higher, increasing significantly.

Therefore, we suggest that urbanization will inevitably produce a heat island effect in urban agglomerations, especially under a complex terrain. Consequently, some effective and ideal measures could be adopted to alleviate the heat island effect caused by urbanization.

\subsection{Mitigation of future heat stress}

Due to the significant urban heat island effect associated with urbanization, to explore reasonable measures to alleviate the urban heat island effect and improve the living comfort of urban residents, we designed the future land-use scenarios. To explore the extent to which the urban heat island effect can be alleviated by returning farmland to forest and grassland and expanding the river lake wetland area of urban agglomeration, we compared the future scenario with the current urban scenario (Fig. 8). In the central part of the CCUA, the average temperature dropped by about $0.5{ }^{\circ} \mathrm{C}$ in summer in July and decreased at night and during the day. The primary cooling interval was $\approx 0.4 \sim 1{ }^{\circ} \mathrm{C}$ and the cooling rate in CQ was higher than that in CD. This situation occurred because that the planned land use is closer to the urban area of CQ than to the urban area of CD. Therefore, the response of CQ to this measure was more obvious in landscape planning.

Comparing the Future scenario (Fig. 9) with the 2018 Urban scenario, it was tedious to find planning measures to reduce the air temperature and ground temperature $2 \mathrm{~m}$ above the CCUA area, CQ area, and $\mathrm{CD}$ area. After the planning, the overall average temperature dropped by $0.2 \sim 0.67^{\circ} \mathrm{C}$, while the daily average PBLH of CCUA, CD, CQ, and other cities dropped 50 150 m in July. Most of the days, the decline was $>100 \mathrm{~m}$.

From comparing the two columns on the right side (Fig.11), the city's heat flux changed after the urban agglomeration planning. With the urbanization scenario in 2018, the average GRDFLX decreased by about $30 \mathrm{~W} / \mathrm{m}^{2}$, the maximum HFX decreased by $38 \mathrm{~W} / \mathrm{m}^{2}$, the $\mathrm{LH}$ increased by $47 \mathrm{~W} / \mathrm{m}^{2}$, and the average Rn increased by $14 \mathrm{~W} / \mathrm{m}^{2}$.

There is a significant difference between the urban heat budget and the natural underlay surface. From the results, we observed that the planning measures have significantly improved the thermal environment of the city because the planned land use increases the natural underlay surface of vegetation and water system. Urban impervious surface and building surface evinced higher surface temperature, which was decisive in the HFX. Whereas, the natural underlay surface dominated the LH, caused by transpiration 
and evaporation of vegetation and wetland. Because the surface temperature was lower than the impervious surface of the city, planning policy can reduce the urban heat island effect and improve the comfort of human settlements.

\section{Conclusions and discussion}

5 We studied the CCUA summer urban warming effect and its adaptation strategies under the complex terrain in Southwest China. In this study, we found that urban land-use types of the CCUA increased to nearly 9,000 square kilometers.. Then, we conducted seven simulations using WRF/SLUCM model with the combined five land-use scenarios, including (History, Urban, No-Urban, and Future Planning Scenarios), and two kinds of terrain (original complex terrain and smoothed terrain).

10 The simulations using 2018 land-use data and original complex terrain showed that the WRF model reproduces a general pattern of summer weather against the observed temperature. In the past 40 years, the changed underlying surface led to the urban heat island effect, increasing the urban temperature by $0.75^{\circ} \mathrm{C}$. The impervious surface absorbed more Rn and stored the energy in the buildings and pavement. The remainder transmitted the HFX to the air through the turbulence exchange, and the HFX rose by > $90 \mathrm{~W} / \mathrm{m}^{2}$, raising the boundary layer. In addition, the transpiration and evaporation from the urban underlay surface decreased, leading to lowering $\mathrm{LH}$ by $\approx 110 \mathrm{~W} / \mathrm{m}^{2}$. These energy balance changes eventually led to temperature rise, and finally to the urban heat island effect. Moreover, the mountainous area around Sichuan Basin is complex in topography, making it difficult for heat to diffuse. This scenario further strengthened the urban heat island effect, enhancing it by $\approx 30 \%$.

20 The simulation for the future planning scenario shows that the implementation of idealized measures (such as returning farmland to forest and river lake expansion) can reduce the urban heat island effect. Likewise, it can regulate the urban ecosystem, such as the average temperature of 2 meters in the summer of urban agglomeration decreased by $\approx 0.2 \sim 0.67^{\circ} \mathrm{C}$. Also, the average net radiation on the surface was reduced by $17 \mathrm{~W} / \mathrm{m}^{2}$. Finally, we anticipate that urban planning policy can provide effective suggestions for future urban thermal environment management and improve living comfort.

\section{Acknowledgments}

This work was supported by the Strategic Priority Research Program of Chinese Academy of Sciences [Grant number: XDA23090102], the National Natural Science Foundation of China (NSFC) project [Grant number: 41830967]. We also thank the National Meteorological Information Center, China Meteorological Administration for data support, and the editor, Dr. Gabriele Messori for his kind comments for the manuscript. 
Table 1 WRF Experimental Design

\begin{tabular}{|c|c|c|c|c|c|}
\hline & & & & & \\
Experimental & WRF Default & History & Urban & No-Urban. & Future \\
\hline No-Topography & Scenario & Scenario & Scenario & Scenario & Scenario \\
\hline Topography & exp.1 & exp.2 & exp.5 & exp.6 & exp.7 \\
\hline
\end{tabular}

Urban effect:

Topography effect:

Urban \& Topography interaction:

Historical changes:

Mitigation of future planning: exp. 3 -exp. 4

exp. 6 - exp. 4

exp. $5-(\exp .3+\exp .6)+\exp .4$

exp. 5 - exp. 2

exp. 7 - exp. 5 


\section{References}

Berling-Wolff, S. ang Jianguo, W. U.: Modeling urban landscape dynamics: a case study in phoenix, USA. Urban Ecosystems, 7(3), 215-240.doi: 10.1023/B:UECO.0000044037.23965.45,2004

Bruinsma, F., and P. Rietveld . "Urban Agglomerations in European Infrastructure Networks." Urban Studies 30.6:919-934. doi:10.1080/00420989320080861,1993

Chen, F., Yang, X., and Zhu, W.: WRF simulations of urban heat island under hot-weather synoptic conditions: The case study of Hangzhou City, China. Atmospheric Research, 138: 364-377, doi: 10.1016/j.atmosres.2013.12.005, 2014

Hamdi R, Schayes G.: Sensitivity study of the urban heat island intensity to urban characteristics. International Journal of Climatology, 7, 973-982, doi: 10.1002/joc.1598, 2010.

Wang, J., Feng, J.M., Yan, Z. W., et al.: Nested high-resolution modeling of the impact of urbanization on regional climate in three vast urban agglomerations in China. Journal of Geophysical Research 117,doi: 10.1029/2012JD018226,2012.

Kalnay E, Cai M.: Impact of urbanization and land-use change on climate. Nature,425,102-102, doi: 10.1038/nature01952,2003.

RyoheiNakamura: Agglomeration economies in urban manufacturing industries: A case of Japanese cities, Journal of Urban Economics,34: 157-175, doi.:10.1016/0094-1190(85)90040-3,1975.

Ning, G., Wang, S., Yim, S. H. L., Li, J., Hu, Y., Shang, Z., et al.: Impact of low-pressure systems on winter heavy air pollution in the northwest Sichuan Basin, China. Atmospheric Chemistry \& Physics 18,13601-13615, doi: 10.5194/acp-18-13601-2018, 2018.

Ning, G., Yim, S. H. L., Wang, S., Duan, B., Nie, C. and Yang, X. .: Synergistic effects of synoptic weather patterns and topography on air quality: a case of the Sichuan Basin of China. Climate Dynamics 11,6729-6744, doi: 10.1007/s00382-019-04954-3, 2019.

Oke, T.R.: The Heat Island of the Urban Boundary Layer: Characteristics, Causes and Effects. NATO Advanced Study Institute on Wind Climate in Cities, 277,81-107,1995.

Richardson, N. J.: Extraordinary denudation in the Sichuan Basin: Insights from low-temperature thermochronology adjacent to the eastern margin of the Tibetan Plateau. Journal of Geophysical 
Research: Solid Earth,B4, B04409, DOI: 10.1029/2006JB004739, 2008.

ROBAA, E.: Effect of Urbanization and Industrialization Processes on Outdoor Thermal Human Comfort in Egypt, Atmospheric and Climate Sciences, 3,100-112. doi:10.4236/acs.2011.13012,2011.

Saitoh, T.S., Shimada, T., and Hoshi, H.: Modeling and simulation of the Tokyo urban heat island. Atmospheric Environment 30, 3431-3442, doi:10.1016/1352-2310(95)00489-0,1996.

Theodore, M., Giannaros, D. M. .: Numerical study of the urban heat island over Athens (Greece) with the WRF model, Atmospheric Environment, 73, 103-111, doi:10.1016/j.atmosenv.2013.02.055. 2013 ,

Ching, J.K.S.: A perspective on urban canopy layer modeling for weather, climate and air quality applications,Urban Climate, 3, 13-39, doi:/10.1016/j.uclim.2013.02.001,2013.

Zhang, M.J., Miao, W.W., Yang, Y.P., Peng, C. and Huang, Y.P.: Spatial-Temporal Features of Wuhan Urban Agglomeration Regional Development Pattern - Based on DMSP/OLS Night Light Data. Journal of Building Construction and Planning Research, 5,14-29,doi:10.4236/jbcpr.2017.51002, 2015.

Wang, J., Feng, J., Yan, Z., and Zha, J.: Urbanization Impact on Regional Wind Stilling: A Modeling Study in the Beijing-Tianjin-Hebei Region of China. Journal of Geophysical Research: Atmospheres ,125, e2020JD033132, doi:10.1029/2020JD033132,2020.

Liu, X. J., Tian, G. J., and Feng, J. M. .: Assessing summertime urban warming and the cooling efficacy of adaptation strategy in the Chengdu-Chongqing metropolitan region of China. Science of The Total Environment, 610-611,1092-1102, doi:10.1016/j.scitotenv.2017.08.082,2018.

Yang, L., Smith, J., and Niyogi, D.: Urban Impacts on Extreme Monsoon Rainfall and Flooding in Complex Terrain. Geophysical Research Letters ,46,5918-59274, doi: 10.1029/2019GL083363,2019.

Yuan, C., Xie, S.: Temporal and spatial visibility trends in the Sichuan Basin, China, 1973 to 2010. Atmospheric Research, 112,25-34, doi:10.1016/j.atmosres.2012.04.009,2012.

Zhao, L., Oleson, K., Bou-Zeid, E., Krayenhoff, E.S., and Oppenheimer, M..: Global multi-model projections of local urban climates. Nat. Clim. Chang, 11,152-157, doi.org/10.1038/s41558-020-009588,2021 . 
https://doi.org/10.5194/esd-2021-22

Preprint. Discussion started: 30 June 2021

(c) Author(s) 2021. CC BY 4.0 License.

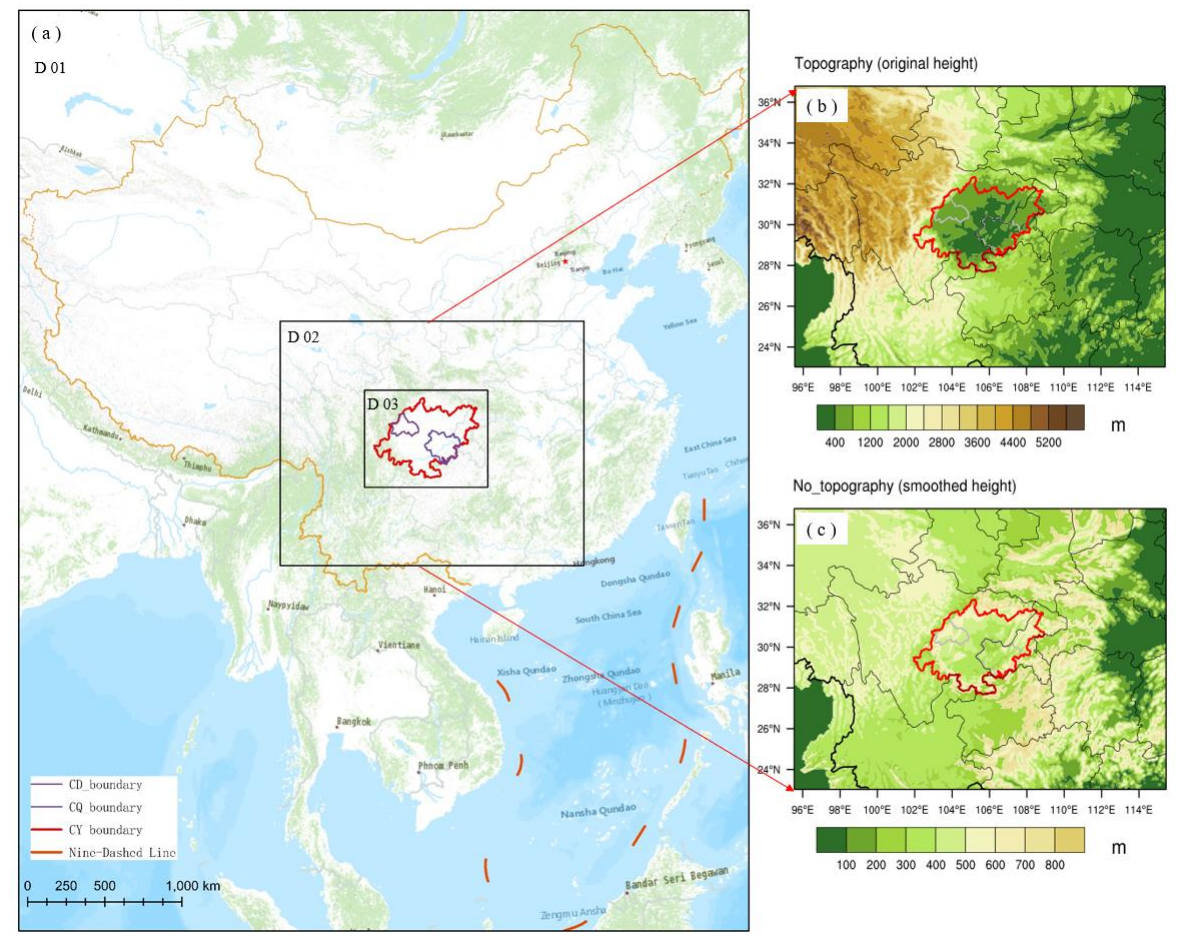

Fig. 1. (a)Configuration of the three nested domains for WRF simulation. (b) The original terrain in the simulated area (m), and (c) after smoothing the terrain. 
https://doi.org/10.5194/esd-2021-22

Preprint. Discussion started: 30 June 2021

(c) Author(s) 2021. CC BY 4.0 License.
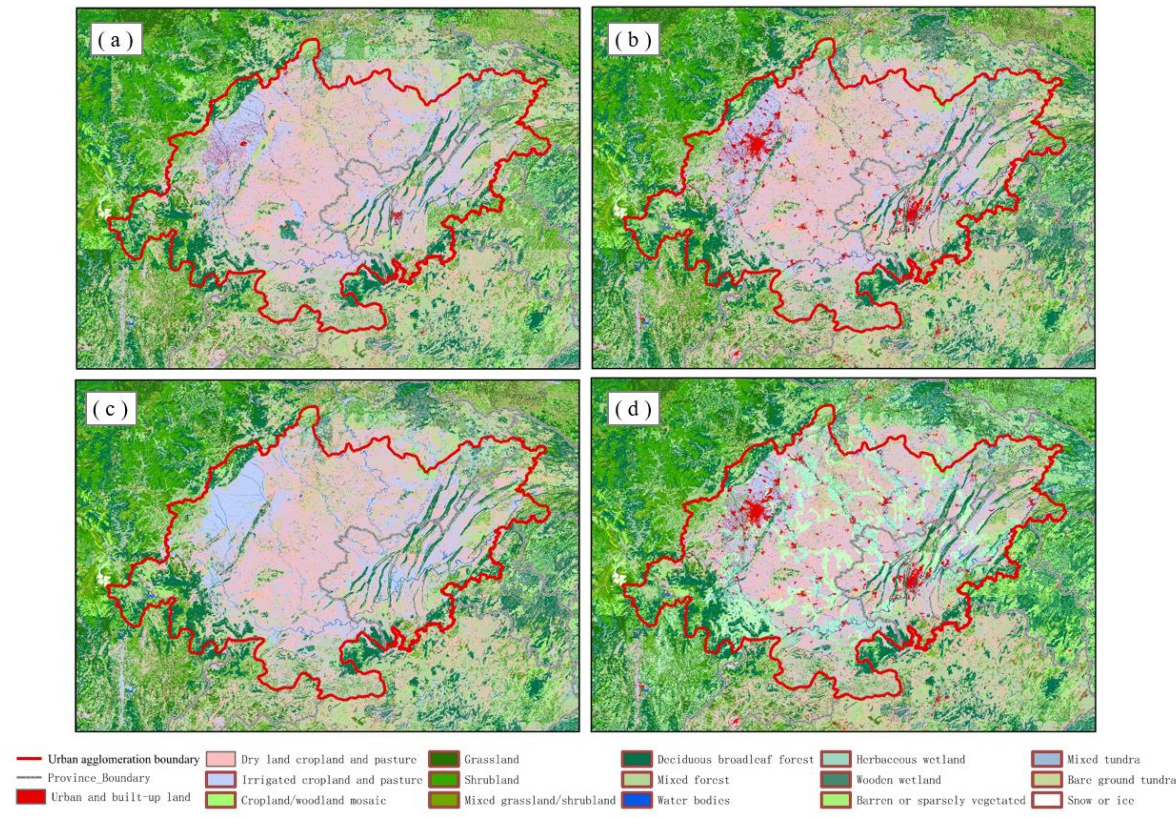

Fig. 2. Land use/land cover in CCUA: (a) 1980; (b) 2018; (c) No-Urban based on 2018 data; and (d) Planned future land use based on 2018 data. 

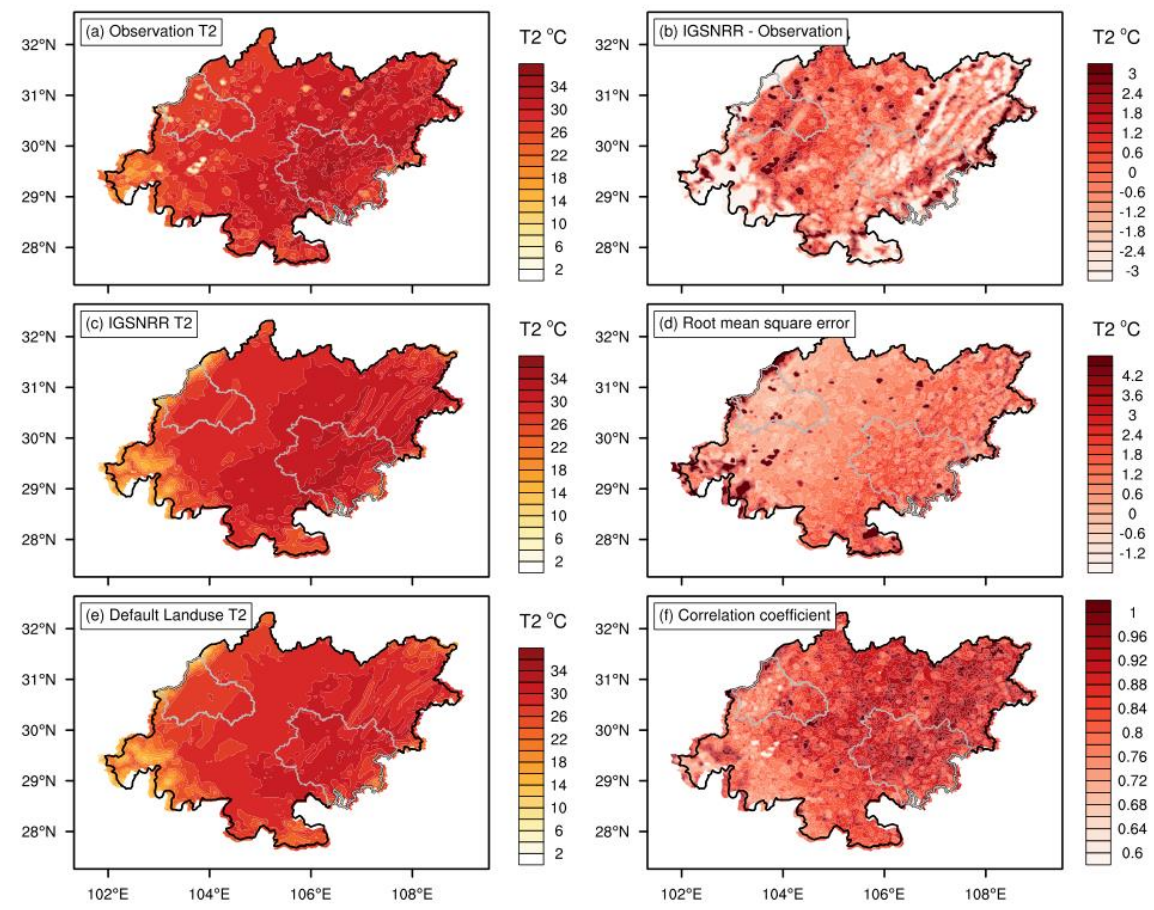

Fig. 3. The $2 \mathrm{~m}$-temperature space distribution of (a) observation data from Cimiss, (b) simulation results with 2018 land-use data from IGSNRR, (c) simulation results with land-use data from WRF default USGS 2010 dataset, (d) simulation of IGSNRR minus observation temperature, (e) root mean square error of $2 \mathrm{~m}$ temperature between observation and IGSNRR simulation results, and (f) correlation coefficient of 2 mtemperature between observation and simulation. 
https://doi.org/10.5194/esd-2021-22

Preprint. Discussion started: 30 June 2021

(c) Author(s) 2021. CC BY 4.0 License.

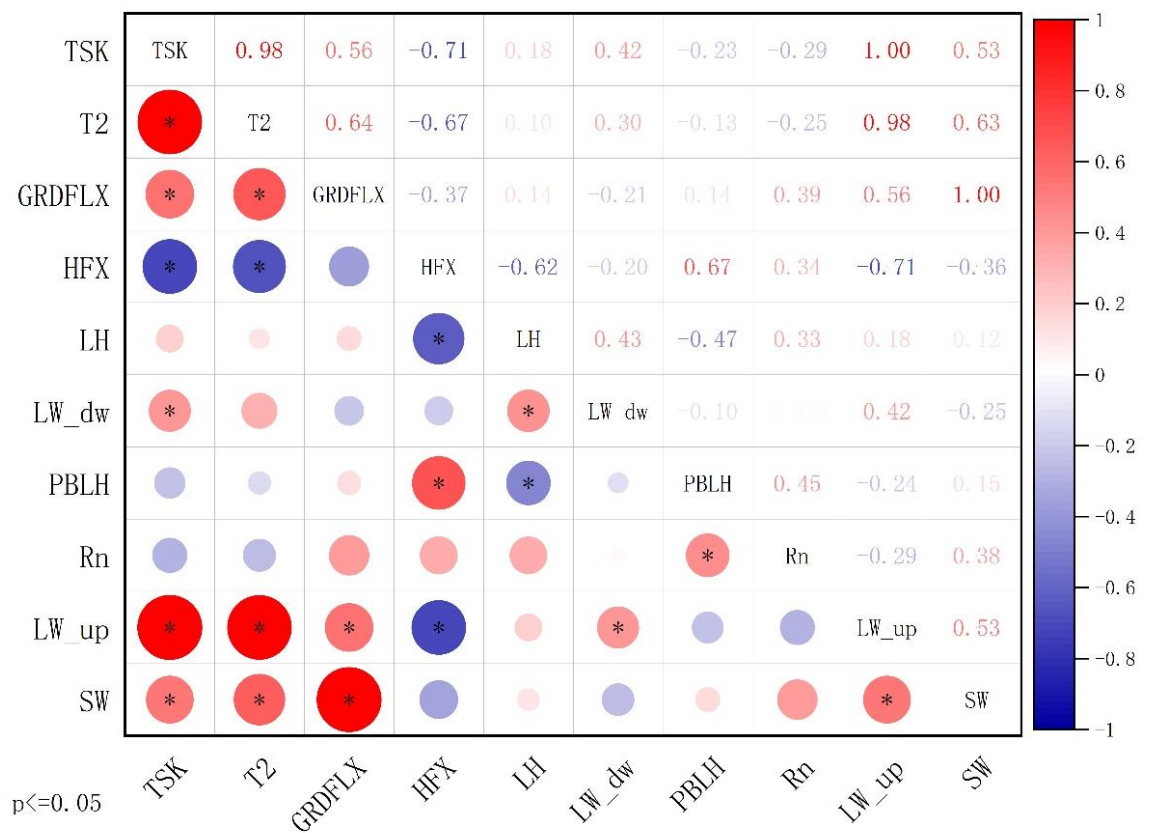

Fig. 4. Pearson correlation coefficient between ten variable of simulation results by WRF with 2018 land use dataset in CCUA. "*” present the variable was passed significant inspection $(p \leq 0.05)$. 
https://doi.org/10.5194/esd-2021-22

Preprint. Discussion started: 30 June 2021

(c) Author(s) 2021. CC BY 4.0 License.

T2 2018Landuse

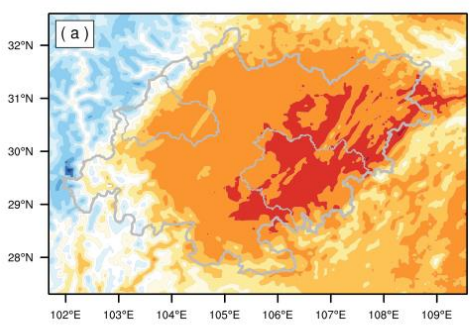

T2_Urban_effect
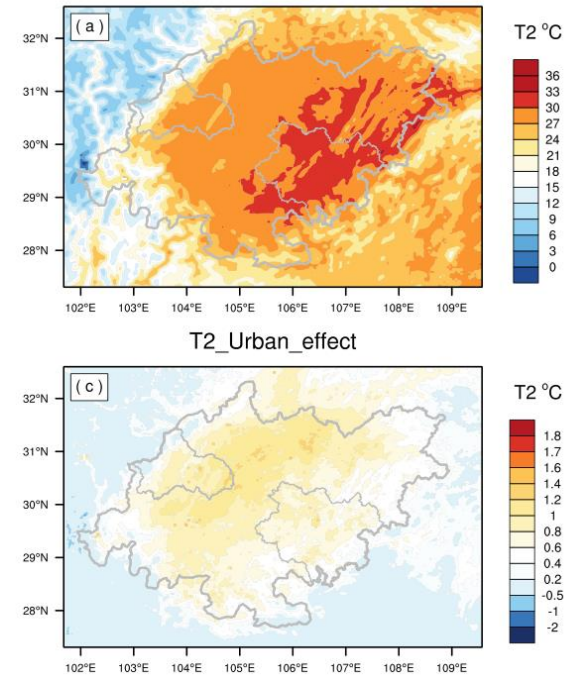

T2 ToPo effect

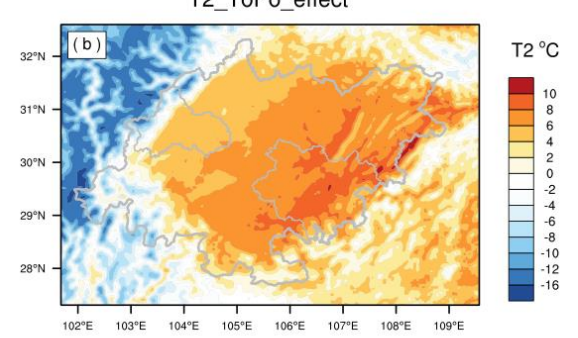

T2_Urban\&ToPo Interaction

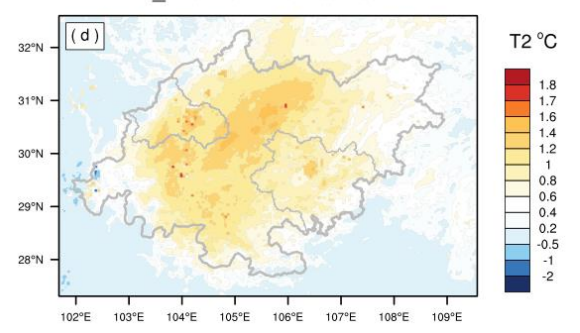

Fig. 5. Effects of urbanization on $2 \mathrm{~m}$ temperature: (a) $2 \mathrm{~m}$ average temperature distribution with 2018 Land use; (b) Topography effect; (c) Urban effect; (d) Urban-Topography Interaction. 

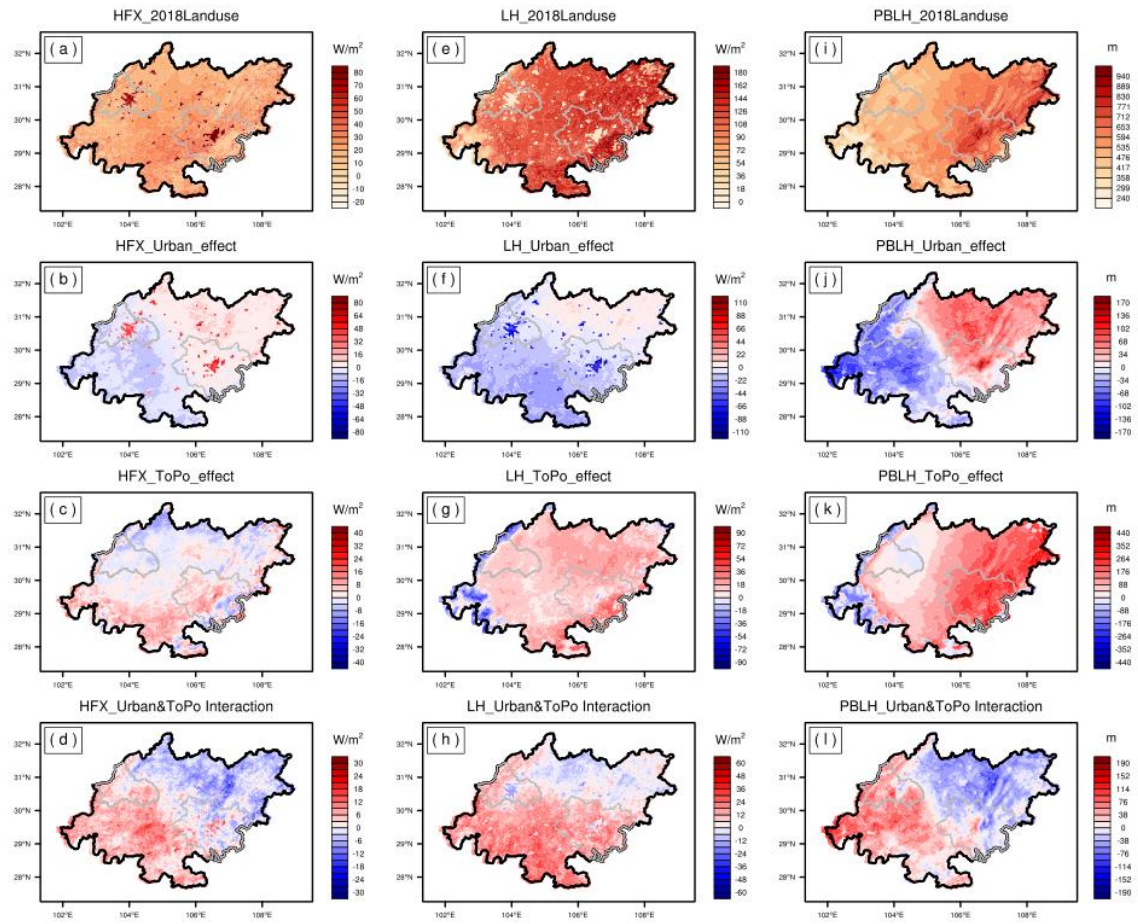

Fig. 6. Influence of urbanization on urban heat flux and PBLH; (a) 2018 Land use Upward HFX; (b)

Influence of urbanization on Urban effect the HFX; (c) Influence of urbanization on urban Topography

effect the HFX; (d) Influence of urbanization on urban Urban \& Topography Interaction effect the HFX;

(e) (h) Influence of urbanization on urban for LH; (i) (l) Influence of urbanization on urban PBLH. 
https://doi.org/10.5194/esd-2021-22

Preprint. Discussion started: 30 June 2021

(c) Author(s) 2021. CC BY 4.0 License.

$2 \mathrm{~m}$ temperature rise $(\mathrm{k})$

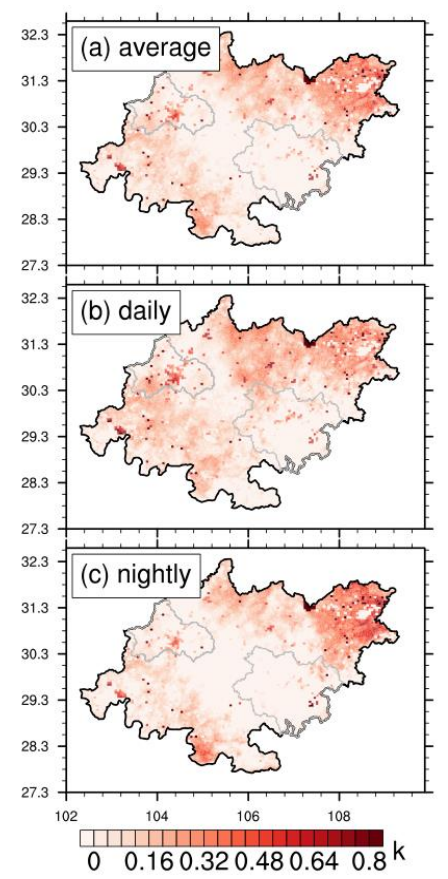

$2 m$ temperature rise $(k)$
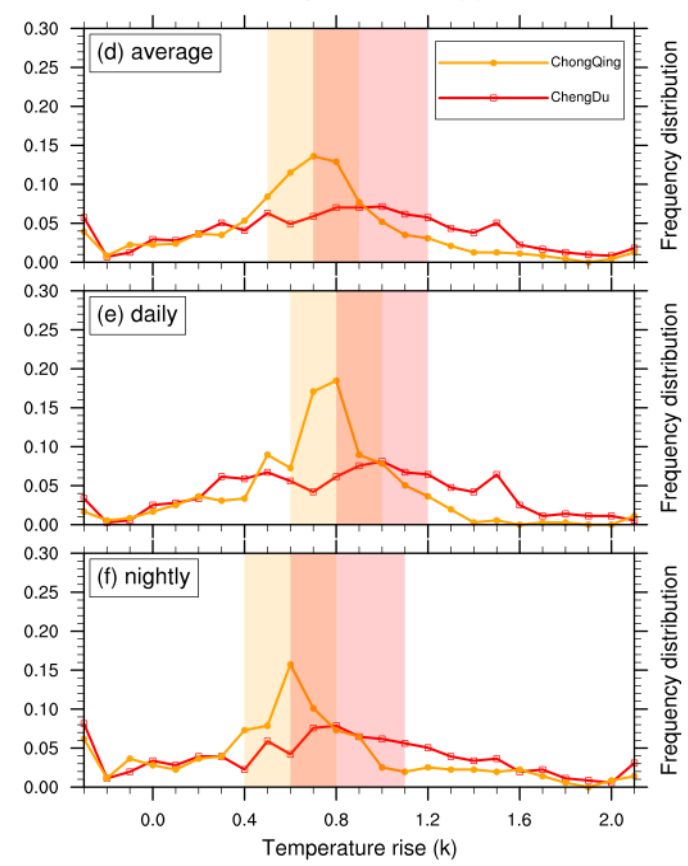

Fig. 7. The spatial distribution of 2 m-temperature rise due to the urbanization, (a) average; (b) daily; and (c) nightly. And the temperature rise frequency distribution: (d) average; (e) daily; and (f) nightly. 

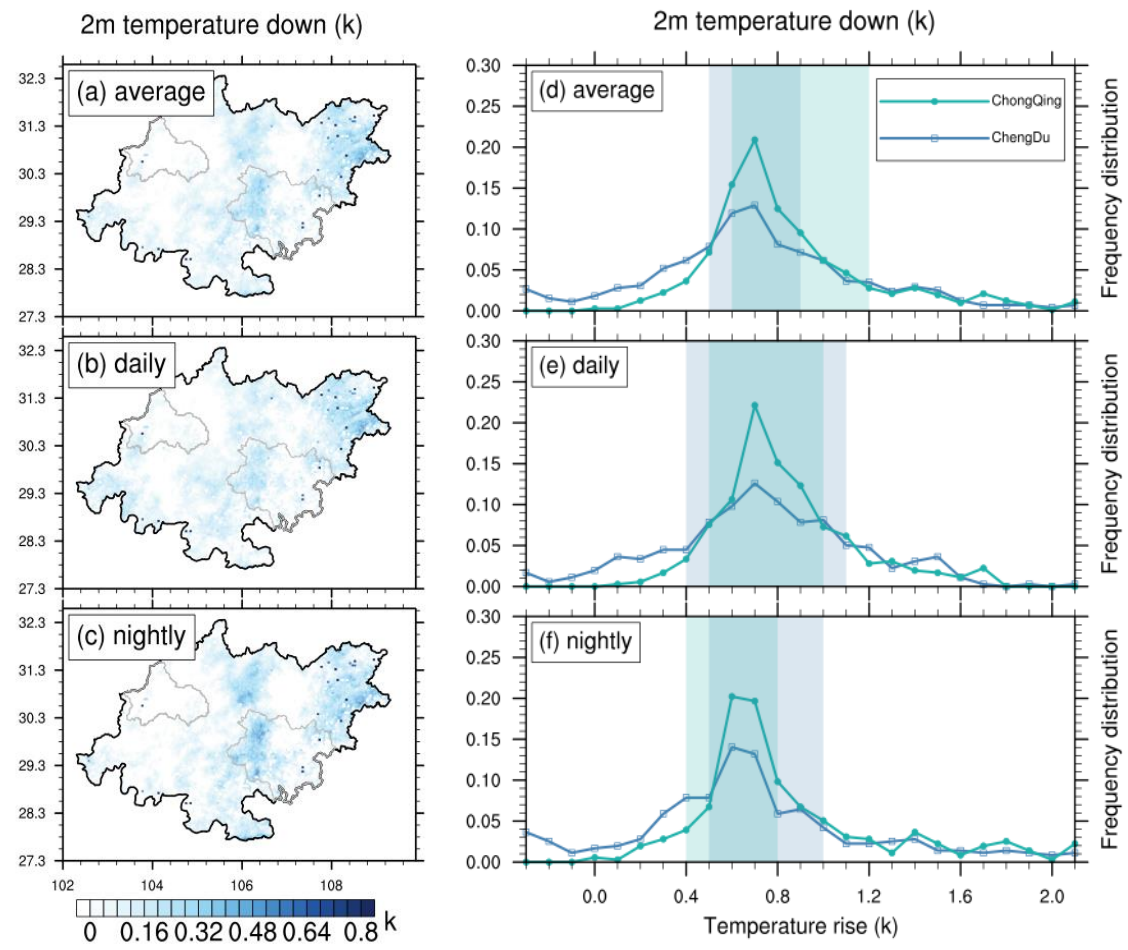

Fig. 8. The spatial distribution of $2 \mathrm{~m}$-temperature cooling because of the future planning scenario, (a) average; (b) daily; and (c) nightly. And the cooling frequency distribution: (d) average; (e) daily; and (f) nightly. 


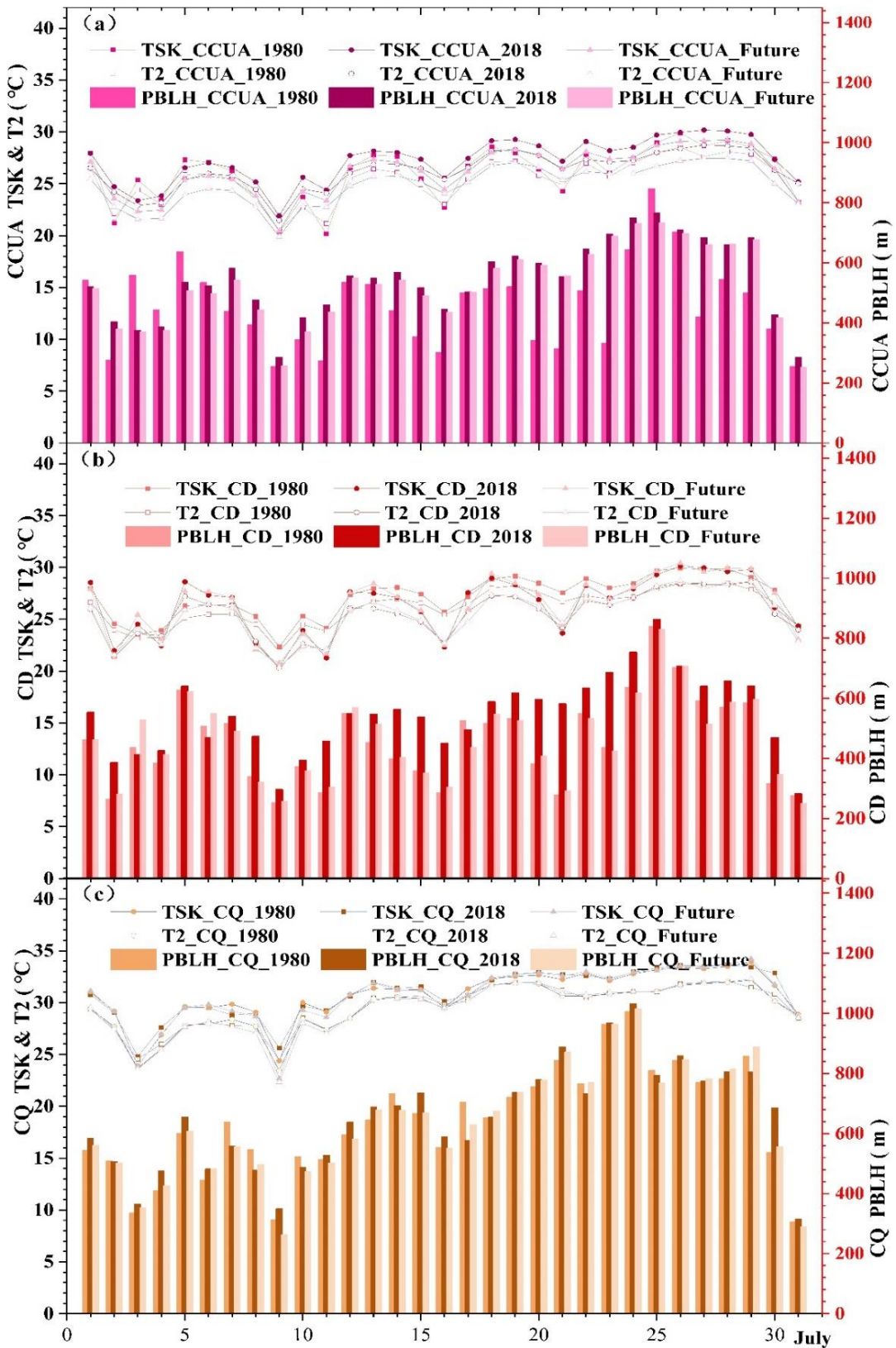

Fig. 9. (a) The TSK and T2 trends, and PBLH distribution over Chengdu-Chongqing Urban Agglomeration; (b)The TSK and T2 trends, and PBLH distribution over ChengDu; (c) The TSK and T2 trends, and PBLH distribution over ChongQing. 
https://doi.org/10.5194/esd-2021-22

Preprint. Discussion started: 30 June 2021

(c) Author(s) 2021. CC BY 4.0 License.

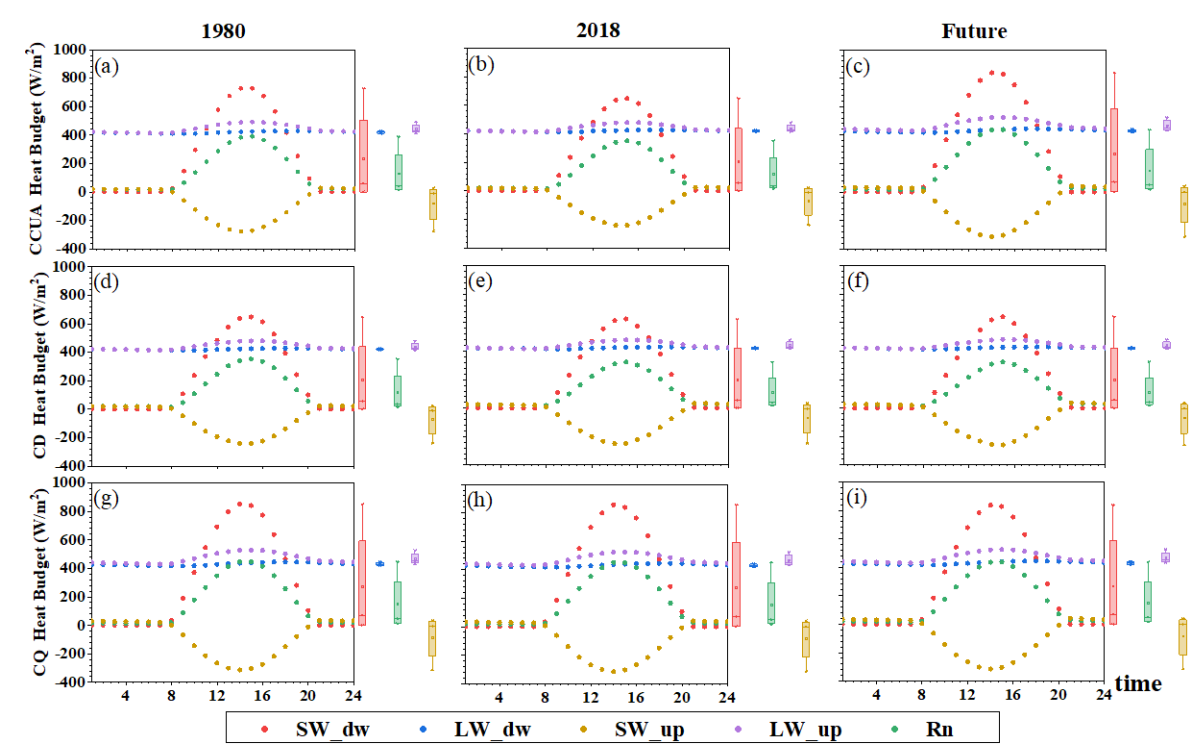

Fig. 10. The diurnal variations in the changes in surface energy budget over the land use grids of 1980, 2018, and future runs of Chengdu-Chongqing Urban Agglomeration . (a) 1980, (b) 2018, and (c)Future. The diurnal variations in the changes in surface energy budget over the land use grids of 1980, 2018, and future runs of ChengDu. (d) 1980, (e) 2018, and (f) Future. The diurnal variations in the changes in surface energy budget over the land use grids of 1980, 2018, and future runs of ChongQing. (g) 1980, (h) 2018, and (i) Future. 
https://doi.org/10.5194/esd-2021-22

Preprint. Discussion started: 30 June 2021

(c) Author(s) 2021. CC BY 4.0 License.

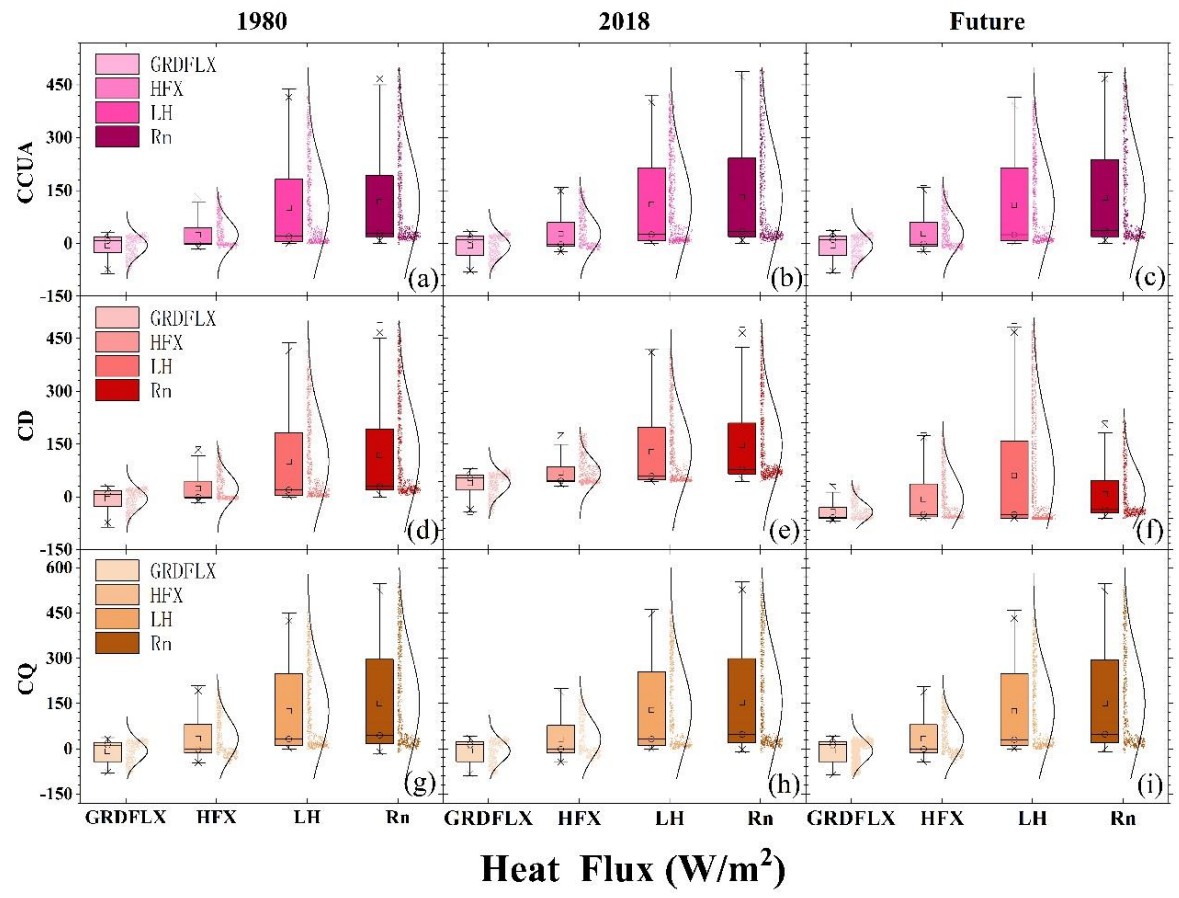

Fig. 11. The heat flux distribution changes in surface heat flux over the land use grids of (a) 1980, (b) 2018, and (c) Future of Chengdu-Chongqing Urban Agglomeration; The heat flux distribution changes in surface heat flux over the land use grids of (d) 1980, (e) 2018, and (f) Future of Chengdu; The heat flux distribution changes in surface heat flux over the land use grids of (g) 1980, (h) 2018, and (i) Future of Chongqing. 